\title{
APRESENTAÇÃO E UMA NOTA SOBRE ALVIN C. PLANTINGA
}

\author{
PresentATION AND A NOTE ON \\ Alvin C. Plantinga
}

Em fins de agosto de 2011, o filósofo norte-americano Alvin Carl Plantinga (1932-) visitou profissionalmente o Brasil. A ocasião para tanto foi o "Simpósio de Filosofia da Religião, Ontologia e Epistemologia Diálogo com Alvin Plantinga", realizado em duas etapas e, de maneira incomum para a forma de eventos na academia brasileira, a cada vez em uma universidade diferente, respectivamente em dois Programas de PósGraduação em Filosofia distintos. A primeira etapa, centrada na filosofia da religião, teve lugar na Universidade de Brasília (25-26.08), e a segunda, com enfoque em epistemologia, aconteceu na Pontifícia Universidade Católica do Rio Grande do Sul (29-30.08). O presente número de Veritas faz um primeiro tributo ${ }^{1}$ a essa visita, incorporando ainda dentro do limite de sua data de publicação como periódico - o mês de agosto do ano corrente - algumas das conferências proferidas na primeira etapa do evento bipartido.

No século passado, e com intensidade incomum no ainda iniciante século 21, um grande número de filósofos importantes, em especial da América do Norte e do continente europeu, visitou o Brasil para engajarse na exposição e no debate de suas convicções. Favor renovado, Alvin Plantinga é inquestionavelmente um dos principais filósofos analíticos da atualidade. Em verdade, a sua formação e atuação como professor e pesquisador são um espelho da ascensão e dos desdobramentos da filosofia analítica no contexto norte-americano. Plantinga obteve o doutorado em filosofia na University of Yale, em 1958. Foi presidente da American Philosophical Association (Divisão Central) de 1981-1982.

1 O segundo tributo está planejado para o segundo número de Veritas em 2012. Editoras diversas e organizadores diversos preparam correntemente a tradução para o português de livros e ensaios de Alvin Plantinga, bem como a publicação de outras coletâneas de estudos diversos sobre a sua obra filosófica.

\begin{tabular}{l|l|l|l|l|r} 
Veritas & Porto Alegre & v. 56 & n. 2 & maio/ago. 2011 & p. 5-17
\end{tabular}


Deixando aqui sem menção a destacada atuação como conferencista internacional e professor visitante, seja mencionado que Plantinga trabalhou em três instituições de ensino superior americanas, a saber, Wayne State University (1958-1963), Calvin College (1963-1982) e, por fim, University of Notre Dame (1982-2010). Na semana em que visitou o Brasil, deixou uma impressão marcante de sobriedade e rigor na exposição e análise de ideias filosóficas, bem como uma imagem de simpatia e modéstia em sua forma de expressão e convivência. É questão difícil dizer qual dos lados foi mais beneficiado no colóquio, mas por certo é justo saber o que esteve em jogo.

Em mais de uma dezena de livros e de uma centena de artigos ${ }^{2}$, Plantinga defendeu teses em filosofia da religião, metafísica e epistemologia que são largamente influentes e debatidas na comunidade filosófica mundial. Cristão convicto e educado na tradição calvinista, em filosofia da religião os seus interesses se voltaram, sobretudo, ao tema clássico da relação entre fé e razão e à busca de formular uma adequada epistemologia da crença religiosa teísta - em que o "teísmo" reúne as convicções de que um Deus pessoal existe, criou o universo e é onipotente, onisciente e infinitamente bom. Nos anos 1960 e 1970, examinou detidamente o alcance das tradicionais "provas da existência de Deus" - dos "argumentos teístas" na filosofia. Nesse período, publicou a antologia The Ontological Argument (1965) e a obra God and Other Minds (1967). Na conclusão desta, acentuou o desempenho modesto da teologia natural no tratamento da crença em Deus, já apontando para a ideia de que a crença em Deus pode ser "básica", no sentido de não ter nem precisar de fundamento em outra crença para que se lhe atribua valor epistêmico. Plantinga também desenvolveu argumentos sobre o assim chamado "problema do mal" em defesa da verdade e/ou da racionalidade da crença teísta, em particular em God, Freedom and Evil (1974). Com o auxílio da lógica modal contemporânea e da semântica dos mundos possíveis, formulou uma "defesa da vontade livre" para mostrar que a existência de Deus, como Ele é entendido nas grandes religiões monoteístas, é compatível com a existência do mal no mundo. Em realidade, a metafísica de Plantinga, para além das teses sobre a existência de Deus (sobretudo a análise do "argumento ontológico", em

2 Diversas publicações têm aparecido que reúnem artigos (e, em alguns casos, republicam capítulos de livros) de Plantinga; dois exemplos são Alvin Plantinga, Essays in the Metaphysics of Modality, ed. by Matthew Davidson, Oxford: Oxford University Press, 2003; Alvin Plantinga, The Analytic Theist - An Alvin Plantinga Reader, ed. by James F. Sennett, Grand Rapids - Cambridge: W. C. Eerdmans, 1998. 
certa medida, ligado historicamente a Anselmo de Cantuária e, mais diretamente, a Descartes e Leibniz), apresenta-se no contexto de teses sobre filosofia da lógica. Foi nessa perspectiva que, em The Nature of Necessity (1974), Alvin Plantinga discutiu os diversos aspectos do conceito de necessidade.

Em Faith and Rationality (1983), obra editada com Nicholas Wolterstorff, Plantinga aprofundou a ideia de a crença em Deus ser "básica" ou, agora, "propriamente básica", ou seja, básica em um sentido adequado ao conhecimento - como o são crenças geradas pela "percepção" e pela "memória". Essa tese, porém, supõe uma crítica à noção de crença básica comum à filosofia moderna, em particular nas epistemologias de Descartes e Locke, que acentuavam que crenças só deveriam ser mantidas em havendo posse, pelo sujeito, de certeza e evidência proposicional. Nessa direção, poder-se-ia bem entender a crítica moderna à racionalidade da crença em Deus, a partir do século 18. Por outro lado, a sua abordagem da crença teísta como "propriamente básica" exigiu também o desenvolvimento da noção de "função própria" (proper function) de uma fonte cognitiva humana, uma condição constitutiva para que crenças verdadeiras sejam adequadamente geradas como o resultado esperado daquelas mesmas fontes de crença.

Assim, em 1993, Plantinga publicou os dois primeiros volumes sobre "aval epistêmico" (warrant): Warrant: the Current Debate e Warrant and Proper Function, os seus principais trabalhos em teoria do conhecimento. Ali, o autor rejeitou as principais teorias sobre o conhecimento como teorias da "justificação" de crenças, em que "justificação" seria aquela qualidade epistêmica positiva que faz de um caso de crença verdadeira um caso de conhecimento. Face à possibilidade de que uma crença seja verdadeira e justificada apenas "acidentalmente" (talvez o resultando principal das críticas de Edmund Gettier, em 1963, à visão clássica do conhecimento como "crença verdadeira justificada"), Plantinga sugere o conceito de "aval" como uma alternativa que não está claramente sujeita a esse problema. Em uma proposta vista na filosofia atual como "externalista", Plantinga entendeu "aval" como uma qualidade que se soma à posse de crença verdadeira e faz dela conhecimento, (i) em havendo "função própria" no mecanismo cognitivo que a produz, (ii) em um ambiente favorável à produção da crença ${ }^{3}$, (iii) segundo um

A segunda condição, do ambiente cognitivo, recebeu grande enfoque na literatura posterior e na recepção da epistemologia de Plantinga; sobre isso, cf. Roberto Hofmeister Pich, Autorização epistêmica e acidentalidade, in: Veritas, 50 (2005):2, p. 249-276. 
plano de desígnio voltado à verdade e, ainda, (iv) segundo um "bom" plano de desígnio do mecanismo cognitivo, isto é, um que, em termos de probabilidade, é "confiável" porque ele gera, em sua maior parte, crenças verdadeiras.

Antes de estender a exposição sumária da epistemologia de Plantinga justamente ao ponto em que ela é aplicada à sua filosofia da religião - ponto em destaque no presente número de Veritas -, tem-se aqui a ocasião de justificar uma versão para o português da terminologia do aparato conceitual de Plantinga. Fala-se, nesse caso, da palavra inglesa "warrant", traduzida, conforme o sentido, como "aval" ou, ainda melhor, "aval epistêmico", mesmo que o adjetivo "epistemic" não conste na forma original. De início, verificou-se a tendência entre estudiosos de Plantinga no Brasil de traduzir "warrant"4 como "garantia", sobretudo por essa ser uma entrada lexical corrente, mesmo que não forçosamente a entrada lexical preferencial. Há muitos motivos pelos quais essa não se revela uma opção feliz, podendo-se indicar ao menos três: (i) ela é mal especificada para o uso em epistemologia de "warrant", a saber, como qualidade de crenças no sentido singular dado por Plantinga. Ora, se alguém diz ter "garantia" para uma crença, é natural que se pergunte "Qual garantia?" ou "Garantia em que sentido?", e disso seria natural esperar como resposta alguma crença certa ou evidente em si ou sobre fatos acerca das fontes cognitivas - o que parece pouco afeito à epistemologia externalista por função própria pretendida por Plantinga. Em resumo, "garantia" não diz de forma virtuosa aquilo que "warrant" adiciona à crença que se tem - em verdade, não é uma palavra que bem especifica uma qualidade de crenças. (b) Além disso, é um critério importante em tradução que, na palavra escolhida, possa-se manter a sua raiz ou o tema para formas diversas de seu uso. Plantinga utiliza basicamente três formas linguísticas de "warrant" e sempre fiel a um mesmo sentido: como substantivo ("warrant" como propriedade de crenças), como verbo ("to warrant", em que a crença é o objeto do uso verbal) e como particípio-adjetivo ("warranted", qualificando a crença, como no uso repetido por Plantinga, a saber, "warranted belief"). Se um mesmo tema de tradução fosse buscado a partir de "garantia", é duvidoso que "garantia" da crença, "garantir a crença" (ou "dar garantia à crença") e "crença garantida" (ou "crença com garantia") possam surtir o efeito

${ }^{4}$ Sem dúvida, Plantinga não foi o primeiro a utilizar "warrant" para fins de avaliação epistêmica, nem é o único em seu tempo. 
esperado tanto em significado (o de ser o substituto desejado para "justificação" e as suas derivações, em inglês ou em português, como em estilo. (c) Finalmente, mesmo em língua inglesa é errado pensar que "garantia" (enquanto sinônimo de "guarantee") tenha de ser a primeira entrada lexical para "warrant"; de fato, o vocábulo parece responder preferencialmente por um sentido legal ou jurídico e de fundamentação, que poderia ser expresso por palavras como "autorização" ou "aval" (para fazer algo), "justificação", "motivo", "fundamentação", antes mesmo de uma "garantia" ou de uma "segurança", seja em sentido jurídico ou circunstancial qualquer ${ }^{5}$.

Claramente, Plantinga utiliza "warrant" como substituto de "justification" ("justificação") e o sentido teoricamente prejudicado que essa expressão-noção adquiriu na epistemologia moderna e do século 20, associado ao evidencialismo e ao deontologismo epistêmico ${ }^{6}$ (cf. abaixo). Caso se deva segui-lo nessa intenção e observar as quatro condições necessárias e em conjunto suficientes para que, dado o desempenho de função própria de uma fonte cognitiva, uma crença tenha "warrant", a versão mais adequada em português parece ser a seguinte: cumpridas as quatro ditas condições, um ente racional tem "autorização" ou "aval", isto é, "autorização epistêmica" ou "aval epistêmico" (para isolar-se dos sentidos jurídicos ou de fundamentação gerais), para a crença, em que isso simplesmente significa (i) uma qualidade que contempla as quatro condições, (ii) têm como expressão na língua vantagens de forma, além da permissão lexical e de sentido, tal que, cumpridas as condições de desempenho epistêmico, "autorizam" ou "avalizam" uma crença, (iii) e finalmente atenuam indicações evidencialistas-deontológicas e mesmo "internalistas" no jogo de avaliação de crenças. Alguém que tem "warrant" para a crença que possui está "em plenos poderes" para tanto, traz, no desempenho epistêmico que realiza, o quadro apropriado de operação.

5 Entende-se que os usos verbais e participiais-adjetivais seguem a lógica dessas considerações sobre o substantivo "warrant". As observações linguísticas aqui feitas têm como base o Oxford Advanced Learner's Dictionary of Current English, Oxford: Oxford University Press, ${ }^{4} 1989$, e o excelente verbete "warrant", in: Langenscheidt - Der grosse Muret-Sanders Encyclopaedic Dictionary of the Englisch and German Languages, Part I English-German (Second Volume N - Z), edited by Dr. Otto Springer, Professor of Germanic Languages and Literatures University of Pennsylvania, Berlin: Langenscheidt, 1996, p. 1630.

6 Cf. Alvin Plantinga, Warrant: the Current Debate, Oxford: Oxford University Press, 1993, Caps. 1-2. 
A obra Warranted Christian Belief (2000) resume o pensamento de Plantinga sobre a epistemologia da crença religiosa, em particular da fé cristã - mesmo levando em conta a literatura posterior produzida por Plantinga, essa pode ser considerada a sua principal obra em filosofia da religião. Nela, o autor reapresentou os principais resultados de sua teoria do conhecimento e aplicou-os à sua filosofia da religião. Em particular, ali, como já em $1993^{7}$, continuou desenvolvendo o seu famoso "argumento evolucionário contra o naturalismo", em que sustenta que a biologia evolucionária, enquanto explicação da evolução das espécies biológicas, relaciona-se muito bem com uma metafísica teísta e, pois, com a religião cristã, ao passo que, contra a opinião comum, a sua relação com o naturalismo metafísico não é boa. Isso se deve ao fato de que é possível mostrar que a crença na conjunção "evolucionismo e naturalismo" é autodestrutiva. O complexo argumento, que, junto com reflexões sobre religião e ciência, ocupou nos anos 2010 a maior parte da produção filosófica de Plantinga ${ }^{8}$, procura mostrar que, na assunção da conjunção de naturalismo materialista e evolucionismo, a probabilidade de que as crenças humanas são produzidas por mecanismos cognitivos confiáveis e são, pois, elas mesmas confiáveis é baixa. Eventualmente, a adoção daquela conjunção torna baixa a confiabilidade de todas as crenças geradas por um ser humano, em especial porque a relação entre crença e comportamento, em uma perspectiva evolucionista-naturalista, não está claramente conectada com a verdade, mas essencialmente comprometida com a sobrevivência ${ }^{9}$.

Como já foi mencionado, a epistemologia de "aval epistêmico" a partir do desempenho por "função própria" de um mecanismo gerador de crenças é aplicada em Fé cristã e aval epistêmico [Warranted Christian Belief] à crença religiosa. Em seu cerne, está a tentativa de contornar a

7 Cf. Alvin Plantinga, Warrant and Proper Function, Oxford: Oxford University Press, 1993, p. $216-237$

8 A mais recente exposição de temas nessa área de interesse é esperada para novembrodezembro do corrente ano, com Alvin Plantinga, Where the Conflict Really Lies: Science, Religion, and Naturalism, Oxford: Oxford University Press, 2011. Cf. ainda Daniel C. Dennett and Alvin Plantinga, Science and Religion - Are they Compatible?, Oxford: Oxford University Press, 2011.

9 Cf. sobre isso, com extensa indicação de literatura de pesquisa, Roberto Hofmeister Pich, Alvin Plantinga e o "argumento evolucionário contra o naturalismo": uma exposição e uma crítica, in: Roberto Hofmeister Pich e Urbano Zilles (orgs.), Filosofia, religião e ciência, Porto Alegre: EST Edições, 2008, p. 69-114. A mais detalhada discussão do "argumento evolucionário contra o naturalismo" se encontra in: James Beilby (ed.), Naturalism Defeated? Essays on Plantinga's Evolutionary Argument Against Naturalism, with a Response by Alvin Plantinga, Ithaca - London: Cornell University Press, 2002. 
visão cliffordiana ${ }^{10}$ de que é sempre "errado" crer em algo "na base de evidência insuficiente". O erro, no caso, equivale à ideia de que, se para a crença religiosa cristã, não existe evidência, essa mesma crença ingressa imediatamente no campo da irracionalidade, irrazoabilidade ou nãojustificação. Nesse caso, tem-se uma questão de iure ou "de direito" (em que a pergunta a ser respondida é se há evidência para crer) distinta de uma questão de facto ou "de fato" (em a pergunta a ser respondida é se a crença é verdadeira porque respectiva a uma proposição verdadeira) ${ }^{11}$.

A questão de iure, segundo Plantinga, foi modernamente, e ainda no século 20, respondida sobretudo por teorias "evidencialistas" de justificação de crenças, como o deontologismo e o fundacionalismo epistêmicos. Nesse caso, pode-se dizer que um sujeito $S$ está justificado em crer em uma proposição $P$ se e somente se a proposição $P$ é "autoevidente", "incorrigível" ou "evidente" à capacidade cognitiva pertinente daquele sujeito, ou então é, redutivamente, crida sob a "base evidencial" de outras proposições que são justificadas daquele modo e dão suporte a ela, de forma dedutiva ou indutiva. Nesses casos, algo é objeto de crença sob "razão" ou "evidência suficiente". Que também a fé cristã ou a crença com conteúdo religioso cristão deveria seguir esse parâmetro rigoroso e máximo de cumprimento de "dever epistêmico", levando em conta as faculdades, as habilidades e os poderes de conhecimento concedidos por Deus, isso Plantinga encontra claramente defendido, por exemplo, por John Locke ${ }^{12}$. Plantinga acredita que essa imagem deontológica "clássica" foi dominante, no que tange à apreciação epistêmica da crença religiosa, até a obra The Miracle of Theism (O milagre do teísmo, 1982), de John Leslie Mackie.

É preciso notar ainda que o quadro apresentado está longe de ser sequer representativo e ainda de ser o mais adequado sobre "racionalidade" e, portanto, sobre o lugar da "racionalidade" na teoria do conhecimento ${ }^{13}$. O debate aqui é fundamental, porque se for admitido que existe uma racionalidade "como função própria", e essa se centra nos "desempenhos da razão" (deliverances of reason) a partir dos mecanismos geradores de crença verdadeira do ser humano, nos casos de desempenho conforme a "função própria", então o entendimento do "evidente" ou antes do

${ }^{10}$ Cf. W. K. Clifford, The Ethics of Belief, in: Contemporary Review, 1877.

${ }^{11}$ Cf., por exemplo, a breve explicação in: Alvin Plantinga, Warranted Christian Belief, Oxford: Oxford University Press, 2000, p. viii-ix.

${ }^{12}$ Cf. Alvin Plantinga, Warranted Christian Belief, Oxford: Oxford University Press, 2000, p. 67-107.

${ }^{13}$ Id. ibid., p. 108-134. 
"autoevidente" e daquilo que dele se segue é modificado, no sentido de que a proposição $P$ crida pelo sujeito $S$ é "racional" se e somente se $\neg P$ "não é um desempenho da razão" operando com função própria. Se uma crença é racional nesses termos, ela tem "aval epistêmico" (warrant) passo em que, notadamente, a conexão entre racionalidade e justificação ou aval é forte.

Em Fé cristã e aval epistêmico, Alvin Plantinga reconhece distintas e decididas críticas ao estatuto epistêmico positivo da crença religiosa (cristã, em particular); assim, destaca-se em Sigmund Freud, por um lado, a classificação da fé cristã lato sensu como "ilusão", cuja força provém da necessidade de satisfação de desejos fundamentais. Destaca-se, por outro lado, em Karl Marx, tanto a origem puramente humana da religião, sobretudo por sua condição histórico-social e, respectivamente, sua consciência alienada, como a apreciação dessa consciência religiosa como suscitada por e exemplificadora de uma "consciência pervertida de mundo". Resumindo a "querela F \& M", para Freud seria o caso que a crença religiosa que é produzida por determinados processos cognitivos "não é dirigida à verdade" (não provém de processos cognitivos veroconducentes); para Marx, a crença religiosa é o produto de "processos cognitivos que funcionam mal", ou seja, não estão eles mesmos, dado o "mundo pervertido", em funcionamento próprio ${ }^{14}$. Nesse contexto, processos cognitivos são desempenhos, em geral, de faculdades cognitivas como "percepção", "memória", "percepção a priori", "sentido moral", "simpatia", "indução", etc., numa lista que Plantinga deve sobretudo a Reid. Também, pois, no horizonte daquelas duas metacríticas a fé cristã não possui aval, sendo o "aval epistêmico" a propriedade que deve ser acrescida à crença verdadeira para que ela seja um caso de conhecimento, segundo, as quatro condições já aludidas. Essa é para Plantinga uma crítica de iure ao teísmo mais plausível e ao mesmo tempo distinta daquelas que são formuladas nos moldes evidencialista ${ }^{15}$. Plantinga defenderá, porém, que há um modelo de "crença teísta avalizada" que pode ser dado pela epistemologia. Ele é um modelo de iure bem sucedido e reivindica um novo olhar à questão de facto.

Trata-se de um modelo por racionalidade como função própria, portanto, respectivo aos desempenhos da razão conforme a função própria dos seus usos ou meio para gerar crença. Nesse sentido, Plantinga encontra como item aceito em tradições cristãs diferentes a ideia de

\footnotetext{
${ }^{14}$ Id. ibid., p. 135-163.

${ }^{15}$ Ibid., p. 161-163, 192-198.
} 
que o ser humano possui, por sua natureza racional e volitiva, um conhecimento original de Deus. Assim, pois, Tomás de Aquino fala de um "conhecimento de modo geral e confuso" da existência de Deus. João Calvino fala de uma "consciência da divindade" (awareness of divinity) na mente humana, certo "entendimento da sua majestade divina", consistindo isso essencialmente na percepção de que existe um Deus e esse é Criador dos seres humano e do mundo. Isso equivale a dizer, segundo Calvino (cf. Institutas I, iii, 1), que se pode falar de um "sentido de divindade" (sensus divinitatis) inscrito no coração humano ${ }^{16}$. Nos termos próprios da epistemologia, Plantinga encontra aqui um "mecanismo cognitivo", dado por natureza, por Deus mesmo, para que crenças sobre Deus sejam produzidas pelo ser humano em determinadas circunstâncias que "acionam" aquela disposição doxástica específica. Assim produzidas, como o seriam, analogamente, crenças perceptuais a seu modo e circunstância, crenças teístas podem perfeitamente ser tomadas como "propriamente básicas" quanto à racionalidade e ao aval epistêmico ${ }^{17}$. Aqui, Alvin Plantinga insiste em mostrar que a questão de iure sobre a "justificação" da crença teísta não é em realidade independente da questão de facto. Afinal, uma determinada crença, como a crença teísta, parece ser "propriamente básica" segundo o "aval epistêmico", se verdadeira ${ }^{18}$.

Para além da crença teísta, Plantinga acredita que o modelo de aval epistêmico por função própria pode ser estendido para a crença teísta especificamente cristã. Feito à imagem e semelhança de Deus, o ser humano por si mesmo caiu em pecado, o que traz como consequências "disfunções" cognitiva e afetiva radicais na sua relação original com a divindade ${ }^{19}$; se, a partir disso, Deus instituiu um "plano de salvação" do ser humano, a forma para tanto teria de ser um esquema de salvação para todos disponível e por todos conhecível. Nesse sentido, Plantinga fala de um "processo cognitivo" que apresenta (a) a Escritura ou a Bíblia, uma coletânea de escritos com autores humanos, mas especialmente inspirados por Deus, de sorte que Deus pode ser entendido como o seu "principal autor"; (b) a presença e a ação do Espírito Santo que foi prometido por Cristo antes da paixão e ressurreição e foi depois invocada e tematizada de várias formas nas epístolas do Apóstolo Paulo;

${ }^{16}$ Ibid., p. 170-175.

${ }^{17}$ Ibid., p. 175-179.

${ }^{18}$ Ibid., p. 190-191.

${ }^{19}$ Ibid., p. 206-227. 
(c) o terceiro elemento do processo cognitivo é a fé, que é a principal obra do Espírito Santo e é produzida "nos corações" dos crentes ${ }^{20}$.

Plantinga aceita, pois, que a fé comporta elemento "cognitivo" e elemento "afetivo" (a decisão da vontade e a percepção da benevolência divina). A fé inclui, e recitando as palavras de João Calvino, "um conhecimento firme e certo da benevolência de Deus", que se funda na "verdade da promessa livremente dada em Cristo", "revelada às nossas mentes" e "selada em nossos corações pelo Espírito Santo" 21. Assim, como restauração da faculdade de conhecimento divino afetada pelo pecado, o processo tripartite pode ser visto como mecanismo, de origem sobrenatural sem dúvida, para geração de crença propriamente básica, de novo interna e externamente "racional" e "avalizada"22. O modelo em si é de iure coerente e não-objetável; objetar a ele teria de significar objetar com sucesso à "verdade" mesma da crença cristã. Como para o aval epistêmico questões de iure e de facto não podem ao final ser distinguidas, pode-se afirmar que, se as crenças cristãs são verdadeiras (aspecto que só pode ser posto a modo condicional, não categórico), é muito provável que tais crenças "de fato" tenham "aval epistêmico"23.

A contribuição de Plantinga à filosofia atual é ímpar. É útil e proveitoso interpretá-lo.

Abrindo a sequência de três estudos sobre Alvin C. Plantinga, Agnaldo Cuoco Portugal, em "Fé, razão e salto no escuro - uma comparação entre Plantinga e Swinburne", analisa o conceito de fé e a justificação racional da fé cristã na obra epocal de Plantinga, a saber, Warranted Christian Belief (2000), na qual a fé cristã é inserida dentro de uma epistemologia da "função própria". No estudo, o autor faz uma comparação temática com o pensamento de Richard Swinburne. Enfatizando as teses de Plantinga de que a fé não é um "salto no escuro" e, ademais, de que o seu componente não-teórico se assemelha ao "amor erótico", Agnaldo Cuoco Portugal faz comparações com a visão de Richard Swinburne, para quem a fé comporta elementos de incerteza e parte de uma "decisão voluntária", motivo pelo qual ela é "meritória". Nesses termos, o autor

\footnotetext{
${ }^{20}$ Ibid., p. 243-244.

${ }^{21}$ Ibid., p. 244.

${ }^{22}$ Ibid., p. 246-289.

${ }^{23}$ Ibid., p. 280-289.
} 
procura indicar algumas complementaridades entre as concepções de Plantinga e de Swinburne.

Em seguida, Marcio de Paula Gimenes, em "Kierkegaard e Plantinga: a subjetividade e a crença em Deus", discute a subjetividade como um fator importante para a afirmação da crença religiosa. No tocante a Kierkegaard e a Plantinga, Marcio Gimenes enfatiza o fato de que os dois autores não têm interesse em provar a existência de Deus, concentram-se antes na "experiência". Apesar de diferenças essenciais entre as duas abordagens, pode-se dizer que, quanto à noção de "subjetividade", em Kierkegaard esse conceito se verifica na afirmação da fé como "absurdo"; já em Plantinga, Márcio Gimenes entende que a "basicalidade da crença" abre espaço para a "experiência" e também aponta para a crença como um item crítico aos fundamentos da modernidade.

Nelson Gonçalves Gomes, em "O argumento ontológico de Plantinga", vê no tratamento do argumento ontológico uma contribuição importante do filósofo norte-americano ao tema clássico da filosofia da religião relativo às "provas da existência de Deus". Após explicitar o contexto histórico do argumento ontológico, Nelson Gomes expõe as pressuposições filosóficas de Plantinga para a sua defesa, ligadas a um "sistema lógico forte". Em especial, no século 20 o argumento ontológico foi retomado no contexto da lógica modal. Aqui, têm peso as reflexões de Leibniz sobre "temas modais", dado que introduz a noção de "mundos possíveis". A filosofia ganhou assim uma forma particular de entender, em termos lógicos, "necessidade", "contingência" e "possibilidade". Fundamental é pensar questões em termos de "diferentes mundos", mesmo a noção de um "Ser Supremo", em que justamente a passagem de um mundo para outros precisa ser justificada. Nelson Gomes destaca o trabalho de C. I. Lewis, no tocante ao esboço do que viria a ser a "lógica modal contemporânea". Foi Lewis quem, em 1932, expôs a série de sistemas modais S1, S2, S3, S4 e S5, em que "S" representa a palavra inglesa "strict". Ali, o sistema S5 é "o menos estrito, o mais simples e também o mais forte, em termos de prova". A partir de dois trabalhos de 1974, a teoria dos mundos possíveis, partindo do S5, foi adotada por Alvin C. Plantinga em seu argumento ontológico, contando esse, sem dúvida, com alguns adendos metafísicos próprios.

Os dois artigos seguintes têm clara proximidade com os temas da filosofia da religião de Alvin Plantinga, a saber, as provas filosóficas da existência de Deus e o debate com a biologia evolucionária contemporânea. Assim, Andrea Luisa Bucchile Faggion, em "Refutação do argumento ontológico, ou filosofia crítica versus filosofia dogmática", lida com as 
defesas de Allen Wood e Norman Malcolm do assim chamado "argumento ontológico" contra as críticas de Immanuel Kant. Andrea Faggion sugere que o argumento kantiano é bem sucedido e que ele é independente dos seus "postulados do pensamento empírico". Antes, a autora procura mostrar que o segundo postulado do pensamento empírico poderia mesmo ganhar justificação em se apelando àquilo que Kant conclui sobre a "existência", na seção famosa "Sobre a impossibilidade de uma prova ontológica da existência de Deus". Por sua vez, João Amazonas MacDowell, em "Evolução versus criação: falso dilema", partindo do fato admitido pela comunidade científica da "evolução cósmica e biológica", busca mostrar que esse parecer científico é compatível com a visão de mundo que inclui um Deus criador. O dilema, pois, exposto no título do artigo é "falso" e provém de um entendimento equivocado do método e, por conseguinte, do alcance das ciências da natureza e da teologia.

Saindo do conjunto de estudos sobre filosofia da religião e sobre a epistemologia da crença religiosa, tem-se inicialmente a continuação e a conclusão do artigo "Confiabilidade, coerência e metaincoerência" ${ }^{24}$, de Emerson Carlos Valcarenghi, cuja primeira parte fora publicada em Veritas 55, 2010:2, p. 60-87. Em seguida, na seção de Varia do presente volume de Veritas, constam dois estudos sobre filosofia na Idade Média e um sobre o grande pensador da Escolástica Barroca, Francisco Suárez.

Em "Sindérese, o intellectus principiorum da razão prática segundo Tomás de Aquino", Carlos Alberto Abertuni investiga a teoria dos primeiros princípios da razão prática segundo Tomás de Aquino, em cujo centro está a "sindérese". Segundo o autor, "sindérese", tendo como termo de comparação a ética aristotélica, designa um conceito inovador na teoria da ação moral. Ele é o "hábito dos primeiros princípios da moral", que tem lugar semelhante ao dos "primeiros princípios teóricos" segundo Aristóteles. Na base disso, destaca-se que o conceito tomasiano de sindérese pode ser entendido através da análise de três aspectos: a sua natureza, a sua infalibilidade e a sua extinção. Em seguida, Sérgio Ricardo Strefling, em "A unidade do poder em Marsílio de Pádua", destaca ideias de Marsílio de Pádua em filosofia política que tiveram influência sobre a modernidade. Em particular, ganha destaque o capítulo 17 da primeira parte da sua obra Defensor Pacis, em que o tópico principal é a

${ }^{24}$ Em Roberto Hofmeister Pich, Apresentação e uma nota sobre Thomas Reid (1710-1796), in: Veritas 55, 2010:2, p. 16, o artigo foi apresentada como "Confiabilidade, coerência e metacoerência"; a palavra "metacoerência", ali, é um lapso, sendo "metaincoerência" o correto. Pedimos desculpas pelo equívoco. 
"unidade do governo". A unidade que defende Marsílio de Pádua é uma "unidade de ordem", e não uma "unidade absoluta".

Finalmente, em "Presencia y disposición de las Disputationes Metaphysicae de Francisco Suárez en el proyecto ontológico-existenciario de Martin Heidegger", Ángel Poncela González explicita os "motivos filosóficos" que levaram Heidegger a inserir a metafísica de Suárez na sua "ontologia existencial". Nesse caso, percorre-se o que Heidegger entendeu ser o "esquecimento do ser" em favor do "ente", como análise crítica precedente à construção da metafísica. Foi central para Heidegger reinterpretar a metafísica grega, sobretudo aristotélica; esse entendimento crítico, assim entende o autor, prejudica em boa parte a sua apreciação da metafísica de Suárez. Na interpretação de Suárez, por Heidegger, sobressai-se o conceito de "existência" e o seu "modo de apreensão" - ao final, ainda um antecedente "imperfeito" do Dasein heideggeriano.

Roberto Hofmeister Pich Felipe de Matos Müller 